This item was submitted to Loughborough's Research Repository by the author.

Items in Figshare are protected by copyright, with all rights reserved, unless otherwise indicated.

\title{
Control of the pore size distribution and its spatial homogeneity in particulate activated carbon
}

PLEASE CITE THE PUBLISHED VERSION

http://dx.doi.org/10.1016/j.carbon.2014.06.054

PUBLISHER

(C) Elsevier

VERSION

AM (Accepted Manuscript)

\section{PUBLISHER STATEMENT}

This work is made available according to the conditions of the Creative Commons Attribution-NonCommercialNoDerivatives 4.0 International (CC BY-NC-ND 4.0) licence. Full details of this licence are available at: https://creativecommons.org/licenses/by-nc-nd/4.0/

\section{LICENCE}

CC BY-NC-ND 4.0

\section{REPOSITORY RECORD}

Hu, Cheng, Saeid Sedghi, S. Hadi Madani, Ana Silvestre-Albero, Hirotoshi Sakamoto, Philip Kwong, Phillip Pendleton, et al.. 2019. "Control of the Pore Size Distribution and Its Spatial Homogeneity in Particulate Activated Carbon". figshare. https://hdl.handle.net/2134/25136. 


\title{
On Control of the Pore Size Distribution and its Spatial Homogeneity in Particulate Activated Carbon
}

Cheng $\mathrm{Hu}^{\mathrm{a}}$, Saeid Sedghi ${ }^{\mathrm{a}}$, S. Hadi Madani ${ }^{\mathrm{b}}$, Ana Silvestre-Albero ${ }^{\mathrm{c}}$, Hirotoshi Sakamoto ${ }^{\mathrm{d}, \mathrm{e}}$, Philip Kwong ${ }^{\mathrm{a}}$, Phillip Pendleton ${ }^{\mathrm{b}, \mathrm{f}}$, Ronald J. Smernik ${ }^{\mathrm{g}}$, Francisco Rodríguez-Reinoso ${ }^{\mathrm{c}}$, Katsumi Kaneko ${ }^{\mathrm{e}}$ and Mark J. Biggs ${ }^{\mathrm{a}}$ **

a. School of Chemical Engineering, The University of Adelaide, SA 5005, Australia.

${ }^{\mathrm{b}}$ Ian Wark Research Institute, University of South Australia, SA 5095, Australia.

c.Laboratorio de Materiales Avanzados, Departamento de Química Inorgánica, Universidad de Alicante, Apartado 99 E-03080, Spain.

${ }^{d}$ Department of Chemistry, Nagoya University, Nagoya, 464-8602, Japan.

${ }^{\mathrm{e}}$ Research Center for Exotic Nano Carbons, Shinshu University, Nagano 380-8553, Japan.

${ }^{\mathrm{f}}$ Sansom Institute, University of South Australia, SA 5001, Australia.

${ }^{g}$ School of Agriculture, Food and Wine, The University of Adelaide, SA 5005, Australia.

\begin{abstract}
There are circumstances where it is desirable to achieve a particular, optimal, pore size distribution (PSD) in a carbon, including in the molecular sieving, gas storage, $\mathrm{CO}_{2}$-capture and electrochemical energy storage. Activation protocols that cycle a carbon a number of times between a lowtemperature oxygen chemisorption process and a higher temperature pyrolysis process have been proposed as a means of yielding such desired PSDs. However, it is shown here that for PFA-based char particles of $\sim 100$ $\mu \mathrm{m}$ in size, only the super-micropores are substantially developed under such an activation protocol, with the ultra-micropores being substantially un-touched. It is also shown that a typical $\mathrm{CO}_{2}$-activation process yields similar control over PSD development. As this process is nearly 15 times faster than the cyclic- $\mathrm{O}_{2}$ protocol and yields larger pore volumes and areas for a given level of conversion, it is to be preferred unless spatial homogeneous porosity within the particles is also desired. If such homogeneity is desired, it is shown here that $\mathrm{CO}_{2}$ activation should continue to be used but at a rate of around one-tenth the typical; this slow rate also has the advantage of producing pore volumes and areas substantially greater than those obtained using the other activation protocols.
\end{abstract}

*mark.biggs@adelaide.edu.au 


\section{Introduction}

Whilst activated carbons are well known to be highly disordered across multiple length scales, there are situations where it is highly desirable to control the pore characteristics. For example, confining the pore size distribution (PSD) tightly around an optimal pore size is advantageous for carbons used in molecular sieving [1], natural gas storage [2], $\mathrm{CO}_{2}$ capture [3], and supercapacitor electrodes [4]. Similarly, it is also sometimes desirable to co-develop both micro and mesopores so as to enhance transport to the micropores $[5,6]$.

The need in some activated carbon applications to have a desired PSD has led to the development of a number of activation protocols that claim to provide a high degree of control over the distribution (e.g. [7-10]). Whilst each of these appears to deliver some degree of control, they are complex and time-consuming compared to the more routinely used methods. Additionally, there is no proof that these more complex protocols yield spatially uniform carbons, an absence of which would not only run counter to the driver for their use, but may also bring other disadvantages. For example, if the desired PSD is localized only to the periphery of a carbon particle $[11,12]$, a rapid degradation in its performance would be likely as it wears during use. Molecular and other models derived from properties of macroscopic volumes of a carbon $[13,14]$ are also less meaningful if spatial variation in the pore structure exists.
In the contribution here, we contrast the control over the PSD and degree of spatial heterogeneity in activated carbon particles obtained from three activation protocols. The first is the controlled activation protocol of Py et al. [8] that involves repeated application of a cycle in which oxygen is first chemisorbed onto the carbon at a moderate temperature (e.g. $\left.250^{\circ} \mathrm{C}\right)$ and then removed along with some of the carbon at a higher temperature (e.g. $800{ }^{\circ} \mathrm{C}$ ) in an inert atmosphere. The second is based on the $\mathrm{CO}_{2}$ activation protocol of Qajar et al. [15], which is typical of industrial practise [16]. The final protocol is the same as the second except at a tenth of the activation rate. The degree of spatial heterogeneity was assessed using a modified form of the procedure developed by Buczek et al. [11, 12], who examined the radial variation of porosity in activated carbon granules. All the activated carbons were derived from a carefully prepared poly(furfuryl alcohol) (PFA) precursor. This precursor was primarily adopted to avoid heterogeneities that would arise from natural precursors such as coal and wood, and because carbons derived from PFA possess broadly similar pore system characteristics of many other polymer-based carbons of increasing interest, including those obtained from phenolic resin and poly(vinylidene chloride) (PVDC) [17].

\section{Experimental Details}

\subsection{Carbon preparation}

\subsubsection{Synthesis of PFA char}

All the carbons considered here were derived from a PFA precursor. To eliminate possible sources of variability in the samples, as-received 
FA (98\%; Sigma-Aldrich, USA) was vacuumdistilled to remove any stabilizers and oxidized and partially-polymerized FA (see the Supplementary Information for further details). To ensure the distillate did not undergo further partial-polymerization or oxidation, it was stored at $-20{ }^{\circ} \mathrm{C}$ under an argon $(99.5 \%$, Coregas, Australia) atmosphere until used.

The FA distillate was mixed with as received oxalic acid dihydrate ( $>99.5 \%$; Ajax, USA) as a polymerization catalyst at 100:3 weight ratio. Mixing was done by careful stirring for $15 \mathrm{~min}$ under argon at $25^{\circ} \mathrm{C}$. Following mixing, $5 \mathrm{~mL}$ of the mixture was transferred to a high-alumina content pyrolysis boat (Coors, USA) of dimensions $90 \mathrm{~mm}$ long by $17 \mathrm{~mm}$ wide by 11.5 mm high. The boat was then loaded into the 200 $\mathrm{mm}$ long midway zone of a horizontal, quartz tube-furnace (Lindberg, USA), where the temperature was constant to within $\pm 1{ }^{\circ} \mathrm{C}$. The contents of the boat were then polymerized and cured to form a thermosetting mass by heating to $150{ }^{\circ} \mathrm{C}$ at a constant rate of $5{ }^{\circ} \mathrm{C} \min ^{-1}$ under a

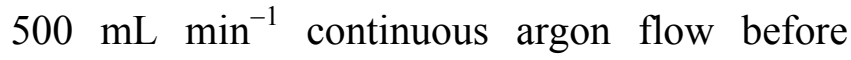
being soaked for 1 hour. Carbonization was then done under the same argon flow conditions by further increasing the temperature to $800{ }^{\circ} \mathrm{C}$ at a constant rate of $5{ }^{\circ} \mathrm{C} \min ^{-1}$ before being soaked for 2 hours. The sample was then finally cooled to room temperature by switching off the furnace whilst continuing the argon flow.

The cooled char was broken up into chunks of around 2-5 $\mathrm{mm}$ in size using a clean zirconia press and then immediately ball-milled (P23,
Fritsch, Germany) and sieved (Cole-Parmer, USA) to obtain a powder with a particle size distribution of 38-106 $\mu \mathrm{m}$. The powder samples were kept in glass vials under an argon atmosphere until used.

\subsubsection{PFA char activation}

Three different activated carbons were considered. The first were derived by applying the cyclic $\mathrm{O}_{2}$ activation protocol of Py et al. [8] to the PFAbased char produced by the process described above. The remaining two activated carbons were obtained by applying $\mathrm{CO}_{2}$ activation to the char at two different rates: that used by Qajar et al. [15], which we estimate to be $9 \%$ conversion per hour (henceforth referred to as fast- $\mathrm{CO}_{2}$ activation), and one-tenth of this rate (henceforth referred to as slow- $\mathrm{CO}_{2}$ activation). The activation processes were all undertaken in the same furnace and boat configuration used to make the PFA char. Samples at both low- and medium-conversion (defined as $25 \%$ and $45 \%$ mass loss after activation, respectively) were produced for all the activation protocols so as to elucidate conversiondependence.

For the cyclic $\mathrm{O}_{2}$-activation protocol, the char was exposed to repeated cycles involving first chemisorption under a $100 \mathrm{~mL} \mathrm{~min}^{-1}$ flow of $\mathrm{O}_{2}$ (99.5\%, Coregas, Australia) at $250{ }^{\circ} \mathrm{C}$ for 8 hours (see Supplementary Information for an explanation of why this period was used) followed by pyrolysis under a $100 \mathrm{~mL} \mathrm{~min}^{-1}$ flow of argon $\left(99.5 \%\right.$, Coregas) at $800{ }^{\circ} \mathrm{C}$ for 2 hours. The low- and medium-conversion carbons, denoted here as $\mathrm{C} 25 \mathrm{O}_{2}$ and $\mathrm{C} 45 \mathrm{O}_{2}$, were obtained 
by undertaking 5 and 9 cycles respectively. The resultant activated carbons were kept in glass vials under an argon atmosphere until used.

Low- and medium-conversion activated carbons from the fast- $\mathrm{CO}_{2}$ activation protocol were obtained by exposing the char to $500 \mathrm{~mL} \mathrm{~min}^{-1}$ $\mathrm{CO}_{2}\left(99.5 \%\right.$, Coregas, Australia) at $900{ }^{\circ} \mathrm{C}$ for 3 and 5 hours, respectively, after initially heating to that temperature from ambient at a rate of $5{ }^{\circ} \mathrm{C} / \mathrm{min}$; these samples are denoted here as $\mathrm{C}_{2} 5 \mathrm{FCO}_{2}$ and $\mathrm{C}_{4} 5 \mathrm{FCO}_{2}$. The same basic procedure was adopted to obtain low- and medium-conversion carbons from the slow- $\mathrm{CO}_{2}$ activation protocol except the maximum temperature was maintained at $805^{\circ} \mathrm{C}$ for 27 and 48 hours respectively; these samples are denoted here as $\mathrm{C}_{2} 5 \mathrm{SCO}_{2}$ and $\mathrm{C}_{4} 5 \mathrm{SCO}_{2}$. The storage of the activated carbons obtained from the $\mathrm{CO}_{2}-$ activation protocols was identical to that of the cyclic $\mathrm{O}_{2}$-activated carbons.

\subsection{Protocol for assessing the radial variation of pore system characteristics}

To assess the spatial variation of the pore system characteristics in the carbon particles considered here, we adopted an approach inspired by Buczek et al. [11, 12], who investigated the radial variation of porosity in granular activated carbons. The powder samples for all but the $\mathrm{C} 25 \mathrm{SCO}_{2}$ carbon [18] were attrited using a ball-mill (P23, Fritsch, Germany) and then sieved to obtain particle cores of decreasing size as well as their peripheries as illustrated in Fig. 1. To minimize particle breakage, the milling was undertaken using relatively mild conditions $(15 \mathrm{~Hz}$ vibration for $2 \mathrm{~min}$ ) in a $5 \mathrm{~mL}$ zirconium oxide bowl containing four zirconium oxide balls of $5 \mathrm{~mm}$ diameter. For each carbon considered, $0.3 \mathrm{~g}$ of the base sample (B) was loaded into the milling bowl and placed under an argon atmosphere before the bowl lid was sealed. After milling (2 min), the attrited peripheral material (P) was removed using a $38 \mu \mathrm{m}$ sieve to leave behind the larger core material $(\mathrm{C} 1)$. This process was repeated to yield a further reduced core (C2) and associated periphery; the latter was not analyzed here due to insufficient mass. It was assumed that after each attrition, the larger particles consisted exclusively of the remaining core of the initial particles.

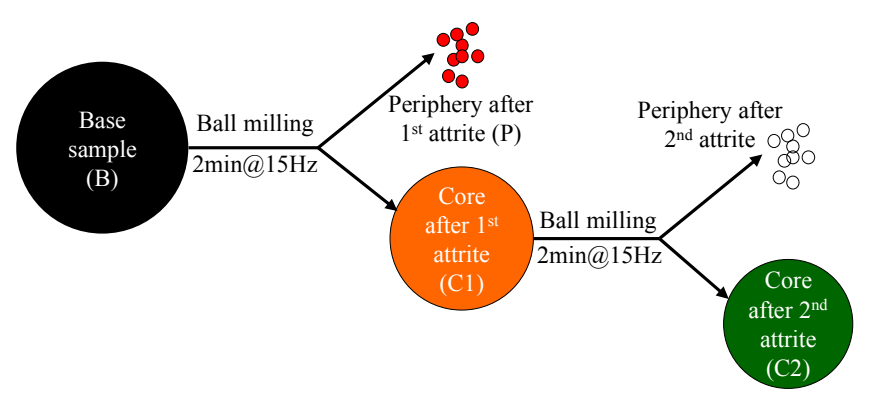

Fig. 1. Protocol to obtain samples that allow assessment of the radial variation of the porosity. The color scheme here is used in Fig. 2, 5 and 7.

The particle size distributions and related parameters of samples $\mathrm{B}, \mathrm{C} 1$ and $\mathrm{C} 2$ from the C45FCO $\mathrm{FCO}_{2}$ carbon are shown in Fig. 2 and Table 1 respectively (see Supplementary Information for details of their determination). As this data shows, the attrition protocol used here resulted in a steady, linear decrease in the mean particle diameter and its dispersion (defined here by $\mathrm{D}[4,3]$ and span, respectively) with degree of attrition. 


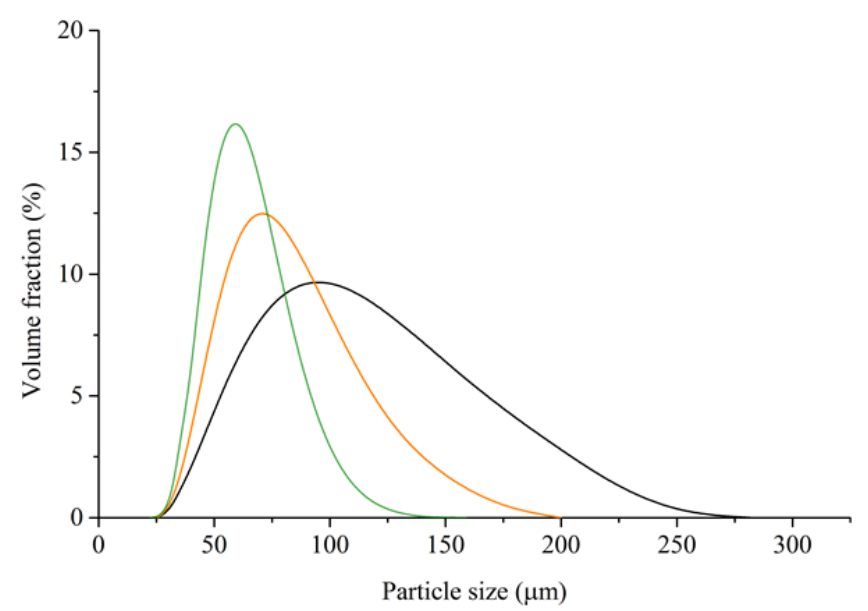

Fig. 2. Particle size distribution of the base $\mathrm{C} 45 \mathrm{FCO}_{2}$ carbon particles before attrition (B; black line) and after the first $(\mathrm{C} 1$; orange line) and second (C2; green line) attritions.

Table 1. Parameters of particle size distributions shown in Fig. 2.

\begin{tabular}{ccc}
\hline Sample & $D[4,3]^{\mathrm{a}}(\mu \mathrm{m})$ & $\mathrm{Span}^{\mathrm{b}}$ \\
\hline $\mathrm{B}$ & 95 & 1.2 \\
$\mathrm{C} 1$ & 72 & 0.9 \\
$\mathrm{C} 2$ & 58 & 0.7 \\
\hline
\end{tabular}

a. Equivalent volume mean diameter.

b. Span $=(D[V, 90]-D[V, 10]) / D[V, 50]$, where $D[V, X]$ is that $\mathrm{X} \%$ of volume below particle size $D$.

\subsection{Porosity characterization}

The pore system characteristics of the carbon samples were determined from $\mathrm{N}_{2}$ gas adsorption isotherms collected at $77 \mathrm{~K}$ using a Micromeritics (USA) ASAP 2020 analyzer. Samples were degassed at $10^{-4}$ torr and $250{ }^{\circ} \mathrm{C}$ for 8 hours. Adsorption was only undertaken provided the leak rate was less than $5 \mathrm{mPa} / \mathrm{min}$. Care was taken to ensure that equilibrium was achieved for all points on the isotherm, with desorption being undertaken to test this down to $P / P_{0} \approx 10^{-1}$ for all

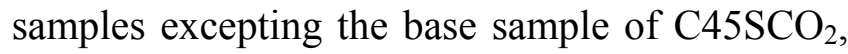
whose desorption isotherm down to $P / P_{0} \approx 10^{-6}$ was determined due to the unusual character of its isotherm compared to the others.
Due to the strong Type I character of the adsorption isotherms, the Rouquerol method [19] was used to obtain the BET specific surface area (SSA), although we recognize this quantity has limited physical meaning here and, as such, we use it more as a reference parameter. PSDs were determined using the quenched solid density functional theory (QSDFT) method [20]. The micropore specific pore volume (SPV) was equated to the cumulative volume determined from the QSDFT method up to $2 \mathrm{~nm}$.

To assess the reliability of the pore system characterization, analysis of the $\mathrm{C} 45 \mathrm{FCO}_{2}$ carbon was repeated four times, keeping all parameters the same. All four isotherms essentially overlapped, and the variation in SSAs and SPVs determined from them were, at most, $\pm 5 \mathrm{~m}^{2} \mathrm{~g}^{-1}$ $(0.43 \%)$ and $\pm 0.005 \mathrm{~cm}^{3} \mathrm{~g}^{-1}(1.17 \%)$, respectively, consistent with uncertainties reported elsewhere $[21,22]$.

\section{Results}

\subsection{Base carbon samples}

Fig. 3 shows the $77 \mathrm{~K} \mathrm{~N}_{2}$ adsorption isotherms of the six base samples (B in Fig. 1); the desorption isotherms, which are provided in the Supplementary Information, indicate no discernable hysteresis. All of the carbons exhibit Type I isotherms, with pore filling appreciably complete within the relative pressure range of $0.4<P / P_{0}<0.5$, indicating they are all essentially microporous in nature with negligible external surface area.

The isotherms for the carbons derived from the cyclic- $\mathrm{O}_{2}$ and fast- $\mathrm{CO}_{2}$ activation protocols are 

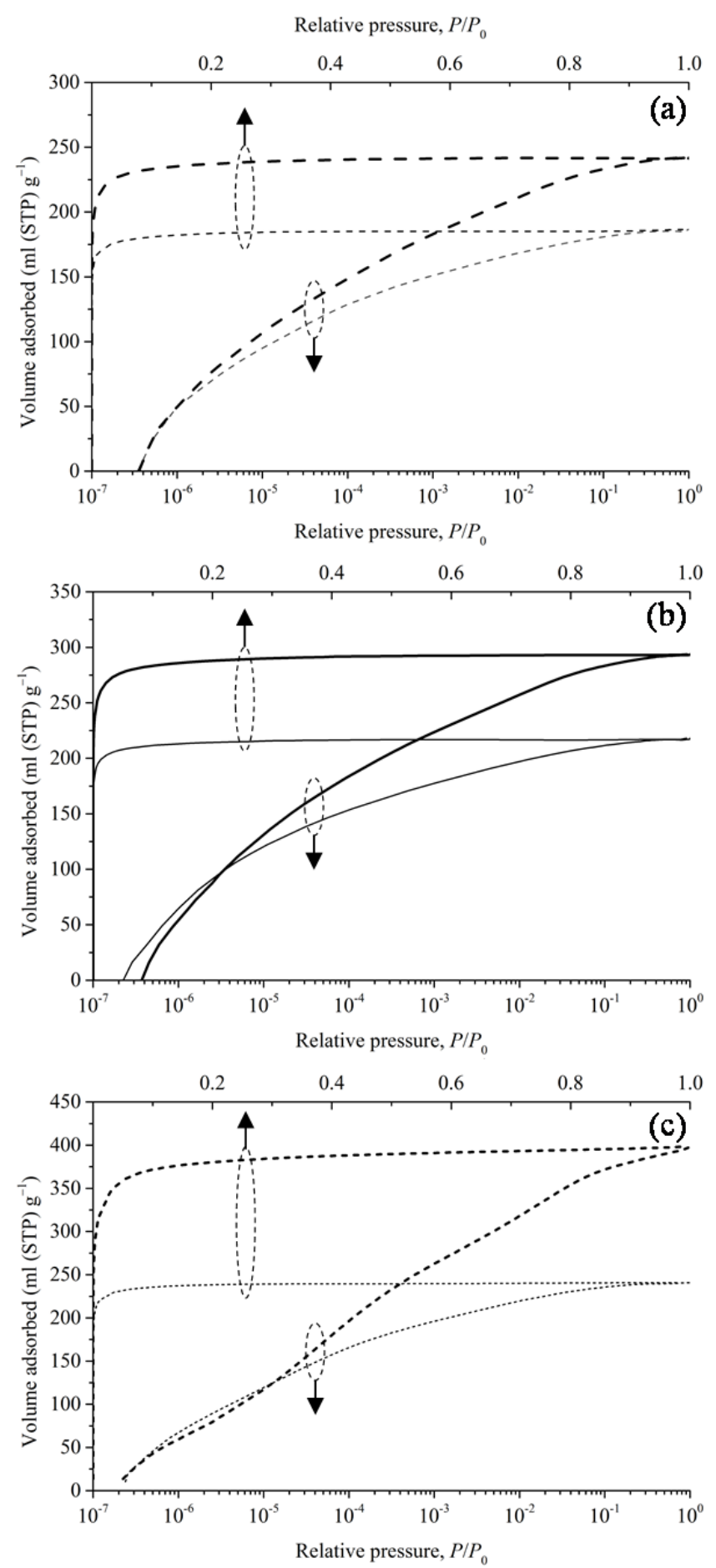

Fig. 3. $\mathrm{N}_{2}$ adsorption isotherms at $77 \mathrm{~K}$ for the six base samples: (a) $\mathrm{C}_{25} 5 \mathrm{O}_{2}$ (thin dashed line) \& $\mathrm{C}_{45} \mathrm{O}_{2}$ (thick dashed line); (b) $\mathrm{C}_{25} 5 \mathrm{FCO}_{2}$ (thin solid line) \& $\mathrm{C}_{45} \mathrm{FCO}_{2}$ (thick solid line); and (c) $\mathrm{C}_{2} 5 \mathrm{SCO}_{2}$ (thin dotted line) \& $\mathrm{C}_{45 \mathrm{SCO}_{2}}$ (thick dotted line).

logarithmically-concave over the entire pressure range, with take-up of nitrogen beginning well below $P / P_{0}=10^{-6}$. Whilst this behavior is also seen for the low-conversion carbon obtained from the slow- $\mathrm{CO}_{2}$ activation protocol, it appears as if the isotherm may be evolving towards a logarithmically-sigmoidal form as conversion progresses, suggesting porosity development under this protocol is fundamentally different from the other two protocols.

Table 2 shows the SPV and SSA are typical of activated carbons of similar burn-off, including PFA-based carbons reported on previously by others [15]. However, the $\mathrm{CO}_{2}$-based protocols yield pore volumes and surface areas that are substantially greater than the cyclic- $\mathrm{O}_{2}$ activation, with the medium-conversion carbon derived from the slow- $\mathrm{CO}_{2}$ activation having values that are some $50-60 \%$ greater than those of its cyclic- $\mathrm{O}_{2}$ activated counterpart.

Table 2. QSDFT-based Micropore Specific Pore Volume (SPV) \& BET-based Specific Surface Area (SSA) of the base samples.

\begin{tabular}{ccc}
\hline Carbon & $\mathrm{SPV}\left(\mathrm{cm}^{3} \mathrm{~g}^{-1}\right)$ & $\mathrm{SSA}\left(\mathrm{m}^{2} \mathrm{~g}^{-1}\right)$ \\
\hline $\mathrm{C} 25 \mathrm{O}_{2}$ & 0.28 & 735 \\
$\mathrm{C} 45 \mathrm{O}_{2}$ & 0.37 & 945 \\
$\mathrm{C}^{2} 5 \mathrm{FCO}_{2}$ & 0.33 & 865 \\
$\mathrm{C} 45 \mathrm{FCO}_{2}$ & 0.45 & 1150 \\
\hdashline $\mathrm{C} 25 \mathrm{SCO}_{2}$ & 0.35 & 965 \\
$\mathrm{C} 45 \mathrm{SCO}_{2}$ & 0.56 & 1510 \\
\hline
\end{tabular}

The Type I isotherm character of the materials is reflected in the PSDs, which are shown in Fig. 4. The differential PSDs for the carbons derived using the cyclic- $\mathrm{O}_{2}$ and fast- $\mathrm{CO}_{2}$ activation protocols reveal two pore size populations for these materials. The first of these is centered sharply around $w \approx 0.55 \mathrm{~nm}$ whilst the second, much broader, population is located in the supermicropore ranges of $0.7<w<1.3 \mathrm{~nm}$. Whilst both populations appear to develop for cyclic- $\mathrm{O}_{2}$ 

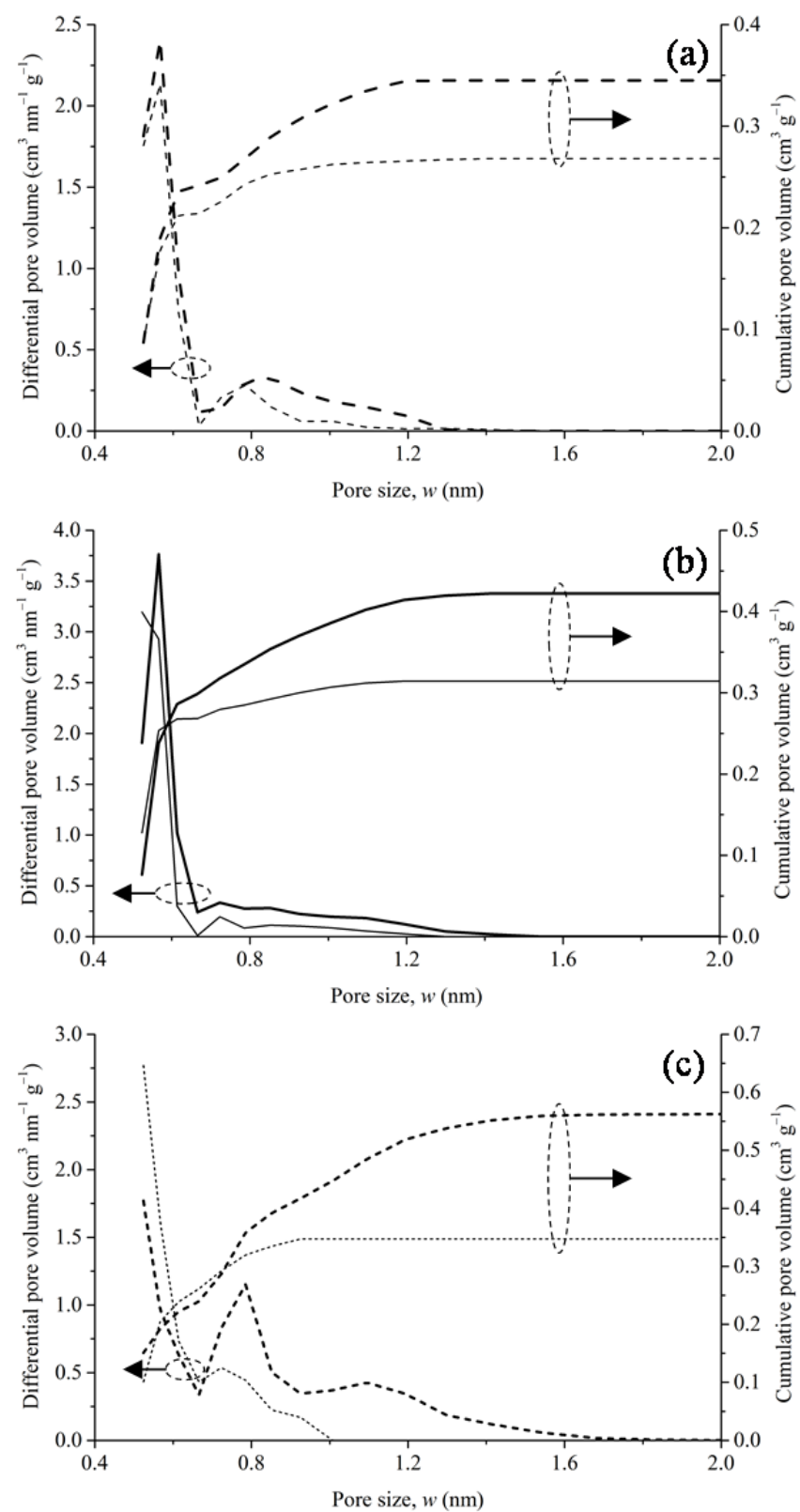

Fig. 4. PSDs for the six base samples derived from the isotherms in Fig. 3: (a) $\mathrm{C}_{25} \mathrm{O}_{2}$ (thin dashed line) \& $\mathrm{C}^{4} \mathrm{O}_{2}$ (thick dashed line); (b) $\mathrm{C}_{2} 5 \mathrm{FCO}_{2}$ (thin solid line) \& $\mathrm{C}_{4} 5 \mathrm{FCO}_{2}$ (thick solid line); and (c) $\mathrm{C}_{2} 5 \mathrm{SCO}_{2}$ (thin dotted line) \& $\mathrm{C}_{45 \mathrm{SCO}_{2}}$ (thick dotted line).

and fast- $\mathrm{CO}_{2}$ activation, the cumulative PSDs reveal the vast majority of the change is confined to the super-micropore range, which is reflected in the growing softness in the isotherm knees for both activation methods ( $c f$. Fig. 3). Comparison of Fig. 4(a) with Fig. 4(b) shows that there are also some differences in the PSD-evolution with conversion for the two activation methods. In particular, the super-micropore development in the cyclic- $\mathrm{O}_{2}$ activation is largely restricted to $0.8-1.2 \mathrm{~nm}$ whilst the range is slightly wider $(0.7-$ $1.4 \mathrm{~nm}$ ) for the fast- $\mathrm{CO}_{2}$ activation protocol. On this basis, it is not unreasonable to assert that the former protocol provides greater control over the PSD development, although the difference is marginal.

The porosity development observed for the slow$\mathrm{CO}_{2}$ activation protocol appears to be fundamentally different in two respects to that seen for the other protocols considered here. Firstly, the volume associated with the supermicropores appears to grow at the expense of the ultra-micropores, which fall in the $0.5<w<0.55$ $\mathrm{nm}$ range. The second difference is the emergence of two populations in the supermicropore range as conversion progresses, the first in the range of $0.7<w<1.0 \mathrm{~nm}$ and the second that stretches over the much wider range of $1.0<w<1.7 \mathrm{~nm}$. This gain in larger micropores at the expense of smaller micropores is, of course, anticipated by the shift from a logarithmically-concave isotherm at lowconversion to a logarithmically-sigmoidal isotherm at medium-conversion, Fig. 3(c). The slow- $\mathrm{CO}_{2}$ activation protocol appears to provide greater control over PSD development compared to the other two protocols in the sense that it shifts porosity from smaller to large pore sizes as conversion increases. However, unlike the other methods, it leads to a slightly wider PSD, which may not be desirable in some circumstances. 


\subsection{Radial variation of pore system characteristics}

Fig. 5 shows the isotherms for the base sample (B in Fig. 2) of the medium-conversion carbons from the three activation protocols $-\mathrm{C}_{45} \mathrm{O}_{2}, \mathrm{C}_{45 \mathrm{FCO}_{2}}$ and $\mathrm{C} 45 \mathrm{SCO}_{2}-$ and the attrited samples derived from them using the protocol shown in Fig. 1 (the low-conversion counterparts for the cyclic- $\mathrm{O}_{2}$ and fast- $\mathrm{CO}_{2}$ protocols are shown in the Supplementary Information). Fig. 5(a) and (c) clearly show that the adsorption isotherms are virtually identical from the peripheral $(\mathrm{P})$ to centre-most $(\mathrm{C} 2)$ fractions derived from the cyclic- $\mathrm{O}_{2}$ and slow- $\mathrm{CO}_{2}$ carbons. Conversely, Fig. 5(b) shows that the isotherms vary radially within the carbon obtained from fast- $\mathrm{CO}_{2}$ activation. This is first-hand evidence that the carbon particles obtained from the cyclic- $\mathrm{O}_{2}$ and slow$\mathrm{CO}_{2}$ activation protocols are spatially homogeneous when $100 \mu \mathrm{m}$ in size (or smaller), whilst the same is not true for the fast $-\mathrm{CO}_{2}$ activation protocol.

To further elucidate the spatial variation of pore system characteristics, Fig. 6 shows the change in SPV and SSA from the periphery sample (P) to centre-most sample (C2) for five of the six carbons considered here [18]. This figure indicates that the SSA for the fast- $\mathrm{CO}_{2}$ activated carbon of medium-conversion varies $7 \%$ from sample-P to sample-C2, well in excess of the variability seen between repeat characterizations for the same sample $(0.43 \%)$. Extrapolating what appears to be a linear variation across the material, the SSA of this carbon could vary up to $18 \%$ (i.e. $200 \mathrm{~m}^{2} \mathrm{~g}^{-1}$ ) from the particle periphery to its centre (assuming an infinitely-small porous core). The SPV for this carbon sees a 5.7\% change from sample-P to sample-C2, suggesting a peripheryto-centre change of around $15 \%$ (i.e. $0.08 \mathrm{~cm}^{3} \mathrm{~g}^{-1}$ ).
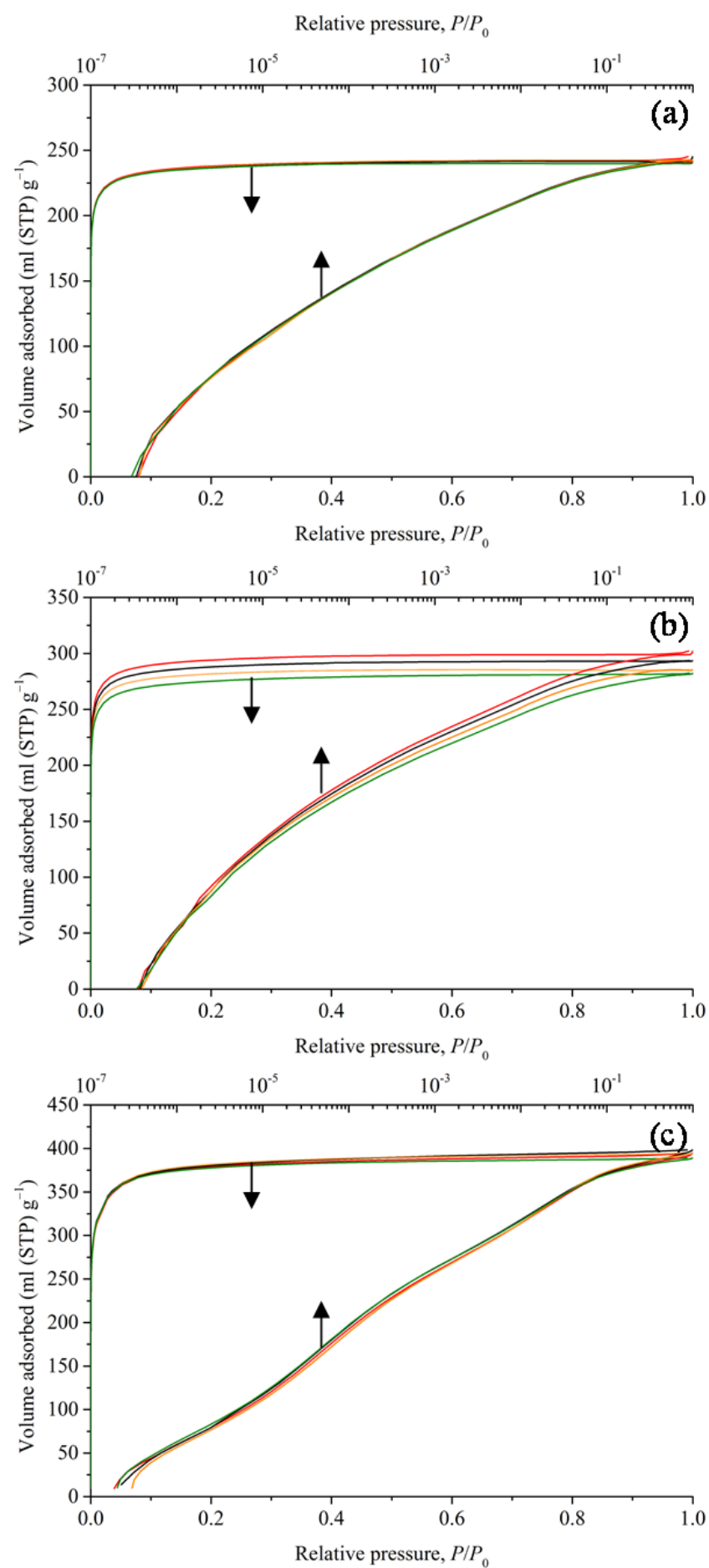

Fig. 5. $\mathrm{N}_{2}$ adsorption isotherms at $77 \mathrm{~K}$ for the $\mathrm{P}$ (red), B (black), C1 (orange) and $\mathrm{C} 2$ (green) samples derived from: (a) $\mathrm{C}_{45} \mathrm{O}_{2}$, (b) $\mathrm{C}_{45} \mathrm{FCO}_{2}$;

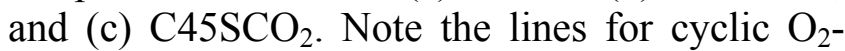
based and slower $\mathrm{CO}_{2}$-based activations are essentially identical and, hence, difficult to discern individually. 
Particle periphery-to-centre changes of around 15\% are similarly estimated for both SPV and SSA of its lower-conversion counterpart. In stark contrast to the fast- $\mathrm{CO}_{2}$ activated carbons, Fig. 6 shows that both the SPV and SSA are, within statistical uncertainty, spatially invariant for the carbons derived using the cyclic- $\mathrm{O}_{2}$ and slow- $\mathrm{CO}_{2}$ protocols, in line with the negligible differences between the isotherms in Fig. 5(a) \& (c).
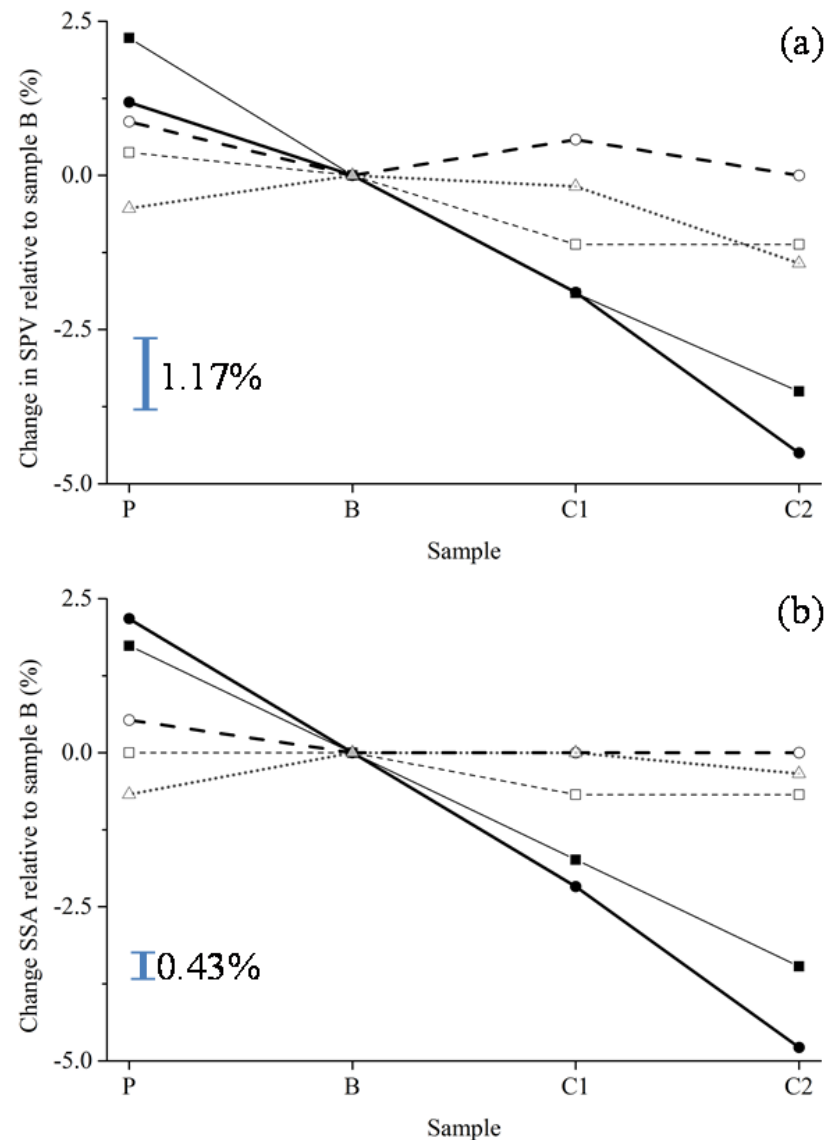

Fig. 6. Variation of pore system characteristics from the periphery samples to the inner-most samples of the $\mathrm{C}_{2} 5 \mathrm{O}_{2}$ (open squares with thin dashed line), $\mathrm{C}_{45} \mathrm{O}_{2}$ (open circles with thick dashed line), $\mathrm{C}_{2} 5 \mathrm{FCO}_{2}$ (closed squares with thin solid), $\mathrm{C}_{45 \mathrm{FCO}_{2}}$ (closed circle with thick solid), and $\mathrm{C}_{45 \mathrm{SCO}_{2}}$ (open triangle with thick dotted line) for: (a) micropore volume; and (b) SSA. The $\%$ bars show the range of variation that is statistically inseparable (cf. Section 2.3).

Fig. 7 shows the PSDs of the $\mathrm{C}_{45} \mathrm{O}_{2}, \mathrm{C} 45 \mathrm{FCO}_{2}$ and $\mathrm{C}_{45 \mathrm{SCO}_{2}}$ samples (the counterparts for the $\mathrm{C} 25 \mathrm{O}_{2}$ and $\mathrm{C} 25 \mathrm{FCO}_{2}$ carbon samples, which are
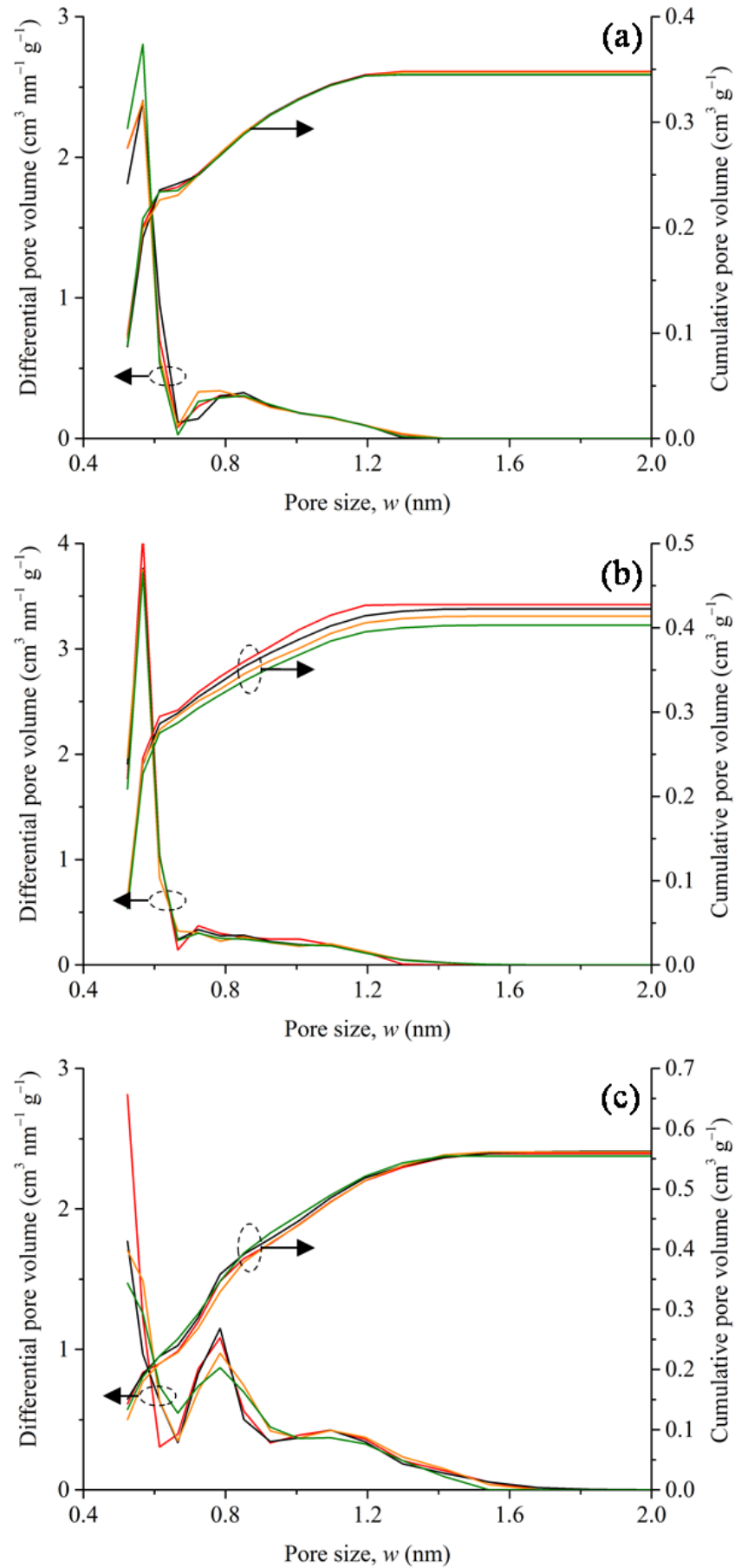

Fig. 7. PSDs for the samples $\mathrm{P}$ (red), B (black), $\mathrm{C} 1$ (orange) and $\mathrm{C} 2$ (green) for: (a) $\mathrm{C}_{4} 5 \mathrm{O}_{2}$; (b) $\mathrm{C}_{45 \mathrm{FCO}}$; and (c) $\mathrm{C}_{45 \mathrm{SCO}_{2}}$.

qualitatively similar, can be found in the Supplementary Information). The PSDs for the cyclic- $\mathrm{O}_{2}$ and slow- $\mathrm{CO}_{2}$ activated samples are essentially invariant from the particle periphery (P) to centre $(\mathrm{C} 2)$, in line with the negligible variation seen in the associated adsorption isotherms. In contrast, for the case of the fast- $\mathrm{CO}_{2}$ 
activated sample, the cumulative distribution function clearly shows that the PSD varies with radial position in the carbon. In particular, the volume associated with micropores beyond 0.6 $\mathrm{nm}$ decreases from particle periphery to centre.

\section{Discussion}

The results outlined above clearly show that both the cyclic- $\mathrm{O}_{2}$ and slow- $\mathrm{CO}_{2}$ activation protocols lead to particles with spatially homogeneous porosity provided they are $100 \mu \mathrm{m}$ or smaller in size. However, comparison of the time taken for the protocols to achieve the same level of conversion or SPV/SSA, Table 3, indicates that the slow- $\mathrm{CO}_{2}$ activation protocol is the most appropriate of those considered here if spatial homogeneity is desired.

Table 3. Time required to achieve indicated sample state.

\begin{tabular}{lc}
\hline Sample & Time (hours) \\
\hline $\mathrm{C}_{45 \mathrm{O}}$ & 117 \\
$\mathrm{C}_{2} 4 \mathrm{O}_{2}$ with $\mathrm{C} 45 \mathrm{SCO}_{2}$ SPV/SSA & 195 \\
$\mathrm{C}^{*} 5 \mathrm{FCO}_{2}$ & 8 \\
$\mathrm{C}_{4} 5 \mathrm{SCO}_{2}$ & 51 \\
\hline
\end{tabular}

* estimated.

The cyclic- $\mathrm{O}_{2}$ activation protocol considered here was previously proposed by Py et al. [8] as a way of carefully controlling pore size development around an optimal value. Our work suggests, however, that the degree of control achieved using their protocol is comparable to that of the fast- $\mathrm{CO}_{2}$ activation protocol and, in the sense of uniform development of porosity during activation, worse than the slow- $\mathrm{CO}_{2}$ activation protocol. Given these observations together with the superior SPVs and SPAs obtained via the $\mathrm{CO}_{2}$ activation protocols and their substantially lower process times, there is little justification for using the method of Py et al. [8].

The contrast in PSD development in the cyclic- $\mathrm{O}_{2}$ and slow- $\mathrm{CO}_{2}$ activation protocols is intriguing. It was argued by Py et al. [8] that allowing $\mathrm{O}_{2}$ chemisorption at temperatures where combustion does not occur (i.e. below $250{ }^{\circ} \mathrm{C}$ ) allows the oxygen to saturate the active sites of the carbon. This assertion certainly appears to be supported by the TGA data here (see Supplementary Information). However, given that this protocol sees only the larger of the two micropore populations in the material develop substantially during activation (see Fig. 4), it appears as if oxygen is essentially restricted to these larger pores at $250{ }^{\circ} \mathrm{C}$. In the slow- $\mathrm{CO}_{2}$ activation protocol, on the other hand, the substantially higher temperature $\left(805^{\circ} \mathrm{C}\right)$ ensures that the oxidant penetrates all pores whilst not reacting so fast as to see diffusion-limited consumption of the particle as clearly occurs in the fast- $\mathrm{CO}_{2}$ activation protocol that takes place at $900^{\circ} \mathrm{C}$.

PFA is a thermosetting polymer that possesses a complex cross-linked structure. This structure is inherited by its char, presenting significantly curved and misaligned graphene layers [23, 24]. The space between the misaligned graphene layers exist as pores of around $0.5 \mathrm{~nm}$ [25]. As similar narrow pores [17] are also obtained in chars derived from other polymers, including PVDC and phenolic resin, the results obtained here are of relevance also to carbons derived from such chars. 


\section{Conclusion}

PFA-based activated carbon particles of around $100 \mu \mathrm{m}$ diameter were subjected to three different activation protocols: (1) the cyclic- $\mathrm{O}_{2}$ activation protocol of Py et al. [8]; (2) fast- $\mathrm{CO}_{2}$ activation (around 9\% conversion per hour); and (3) slow$\mathrm{CO}_{2}$ activation (around $0.9 \%$ conversion per hour). The first of these protocols led to a spatially uniform development of the porosity within the particles. The two populations that characterize its pore size distribution (PSD) - one located in the ultra-micropore range $(0.55 \mathrm{~nm})$ and a second in the super-micropore range (0.8$1.2 \mathrm{~nm})$ - did not, on the other hand, develop uniformly, with only the latter changing substantially during activation. The cyclic- $\mathrm{O}_{2}$ activation protocol also yielded the smallest specific pore volume (SPV) and BET specific surface area (SSA) of the three protocols. Whilst the PSD of the carbon obtained from the fast- $\mathrm{CO}_{2}$ activation protocol was similar to its $\mathrm{O}_{2}$-cyclic counterpart, significant radial variation in the porosity was observed, with the SPV and SSA estimated to decrease by $15-18 \%$ from particle periphery to centre. No such radial variation was seen in the carbons derived from the slow- $\mathrm{CO}_{2}$ activation protocol despite it still being more than two times faster than the cyclic- $\mathrm{O}_{2}$ protocol. Moreover, this protocol led to all pores growing in size and the highest SPV and SSA of all the protocols. These results indicate that the slow$\mathrm{CO}_{2}$ activation protocol is the best of the three considered here if spatial uniformity within the particles is desired in addition to control over PSD development.
The effect that particle size has on the degree of spatial homogeneity within particles for the different protocols considered here is clearly of interest. As such, work is currently underway to address this question and a report will appear in due course. The similarity between the pore structures of PFA-based carbons and those derived from other non-graphitizing chars (e.g. those derived from phenolic resin and PVDC) suggests that the conclusions of the work here will also apply to these other carbons. It would, however, be of interest to confirm this hypothesis.

\section{Acknowledgements}

$\mathrm{CH}$ acknowledges a joint scholarship provided by China Scholarship Council (CSC) and the University of Adelaide. SS acknowledges the award of International Postgraduate Research Scholarship (IPRS) from the University of Adelaide. SHM acknowledges the award of a President's Scholarship from the University of South Australia. The support of the Australian Research Council Discovery Program (DP110101293) is also gratefully acknowledged.

\section{References}

[1] Verma SK, Walker Jr PL. Alteration of molecular sieving properties of microporous carbons by heat treatment and carbon gasification. Carbon 1990; 28(1):175-84.

[2] Celzard A, Fierro V. Preparing a suitable material designed for methane storage: A comprehensive report. Energy Fuels 2005; 19(2):573-83.

[3] Silvestre-Albero J, Wahby A, SepúlvedaEscribano A, Martínez-Escandell M, Kaneko K, Rodríguez-Reinoso F. Ultrahigh $\mathrm{CO}_{2}$ adsorption capacity on carbon molecular sieves at room temperature. Chem Comm 2011; 47(24):68406842. 
[4] Simon P, Gogotsi Y. Materials for electrochemical capacitors. Nat Mater 2008; 7(11):845-54.

[5] Quinn DF, Holland JA. Carbonaceous material with high micropore and low macropore volume and process for producing same. US patent 5071820, 1991.

[6] Lei S, Miyamoto J, Kanoh H, Nakahigashi Y, Kaneko K. Enhancement of the methylene blue adsorption rate for ultramicroporous carbon fiber by addition of mesopores. Carbon 2006; 44(10):1884-90.

[7] $\mathrm{Hu} \mathrm{Z}$, Vansant EF. Synthesis and characterization of a controlled-micropore-size carbonaceous adsorbent produced from walnut shell. Micropor Mater 1995; 3(6):603-12.

[8] Py X, Guillot A, Cagnon B. Activated carbon porosity tailoring by cyclic sorption/decomposition of molecular oxygen. Carbon 2003; 41(8):1533-43.

[9] Williams HM, Dawson EA, Barnes PA, Parkes GMB, Pears LA, Hindmarsh CJ. A new low temperature approach to developing mesoporosity in metal-doped carbons for adsorption and catalysis. J Porous Mater 2009; 16(5):557-64.

[10] Mysyk R, Gao Q, Raymundo-Piñero E, Béguin F. Microporous carbons finely-tuned by cyclic high-pressure low-temperature oxidation and their use in electrochemical capacitors. Carbon 2012; 50(9):3367-74.

[11] Buczek B, Świątkowski A, Ziętek S, Trznadel BJ. Adsorption properties and porous structure within granules of activated carbons with different burn-off. Fuel 2000; 79(10):124753.

[12] Deryło-Marczewska A, Goworek J, Świątkowski A, Buczek B. Influence of differences in porous structure within granules of activated carbon on adsorption of aromatics from aqueous solutions. Carbon 2004; 42(2):301-6.

[13] Biggs MJ, Buts A. Virtual porous carbons: what they are and what they can be used for. Mol Sim 2006; 32(7):579-93.

[14] Palmer JC, Gubbins KE. Atomistic models for disordered nanoporous carbons using reactive force fields. Micropor Mesopor Mater 2012; 154(0):24-37.
[15] Qajar A, Peer M, Rajagopalan R, Liu Y, Brown C, Foley HC. Surface compression of light adsorbates inside microporous PFA-derived carbons. Carbon 2013; 60:538-61.

[16] Marsh H, Rodríguez-Reinoso F. Activation processes (thermal or physical). In: Marsh $\mathrm{H}$, Rodríguez-Reinoso F, editors. Activated Carbon. Oxford: Elsevier Science Ltd; 2006, p. 243-321.

[17] Foley HC. Carbogenic molecular sieves: synthesis, properties and applications. Micropor Mater 1995; 4(6):407-33.

[18] The low-conversion carbon obtained from the slow- $\mathrm{CO}_{2}$ activation was not assessed for the degree of radial heterogenuity because, as will be seen, the medium-conversion carbon obtained via this protocol showed no radial variation.

[19] Rouquerol J, Llewellyn P, Rouquerol F. Is the BET equation applicable to microporous adsorbents? In: Llewellyn PL, Rodríguez-Reinoso F, Rouquerol F, Seaton N, editors. Studies in Surface Science and Catalysis, Elsevier; 2007, p. 49-56.

[20] Neimark AV, Lin Y, Ravikovitch PI, Thommes M. Quenched solid density functional theory and pore size analysis of micromesoporous carbons. Carbon 2009; 47(7):161728.

[21] Badalyan A, Pendleton P. Analysis of uncertainties in manometric gas-adsorption measurements: II. Uncertainty in $\alpha_{\mathrm{s}}$-analyses and pore volumes. J Colloid Interface Sci 2008; 326(1):1-7.

[22] Badalyan A, Pendleton P. Analysis of uncertainties in manometric gas-adsorption measurements. I: Propagation of uncertainties in BET analyses. Langmuir 2003; 19(19):7919-28.

[23] Burket CL, Rajagopalan R, Marencic AP, Dronvajjala K, Foley HC. Genesis of porosity in polyfurfuryl alcohol derived nanoporous carbon. Carbon 2006; 44(14):2957-63.

[24] Smith MA, Foley HC, Lobo RF. A simple model describes the PDF of a non-graphitizing carbon. Carbon 2004; 42(10):2041-8.

[25] Mariwala RK, Foley HC. Evolution of ultramicroporous adsorptive structure in poly(furfuryl alcohol)-derived carbogenic molecular sieves. Ind Eng Chem Res 1994; 33(3):607-15. 


\section{Supplementary Information}

\section{On Control of the Pore Size Distribution and its Spatial Homogeneity in Particulate Activated Carbon}

Cheng $\mathrm{Hu}^{\mathrm{a}}$, Saeid Sedghi ${ }^{\mathrm{a}}$, S. Hadi Madani ${ }^{\mathrm{b}}$, Ana Silvestre-Albero ${ }^{\mathrm{c}}$, Hirotoshi Sakamoto ${ }^{\mathrm{d}, \mathrm{e}}$, Philip Kwong $^{\text {a }}$, Phillip Pendleton ${ }^{\text {b,f }}$, Ronald J. Smernik ${ }^{\mathrm{g}}$, Francisco Rodríguez-Reinoso ${ }^{\mathrm{c}}$, Katsumi Kaneko ${ }^{\mathrm{e}}$ and Mark J. Biggs ${ }^{\mathrm{a}, *}$

\section{Distillation of as-received FA}

The as-received FA (98\%; Sigma-Aldrich, USA), left-hand side of Fig. S1, was vacuum-distilled $\left(\approx 1.33 \mathrm{~Pa}\right.$ and $\left.60{ }^{\circ} \mathrm{C}\right)$ to remove any stabilizers, and oxidized or partially polymerized FA. The purity of the obtained distillate (right-hand side of Fig. S1) was tested by gas chromatography (GC).

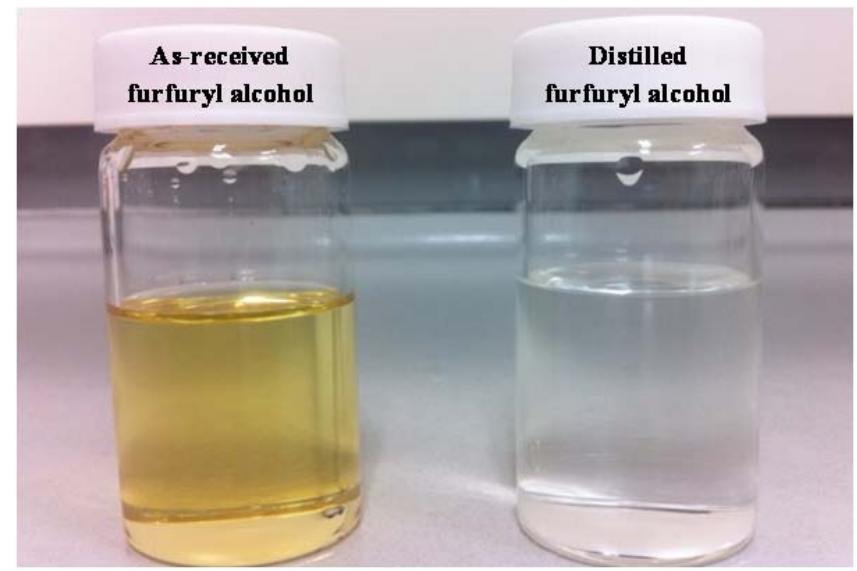

Fig. S1. Appearance of as-received FA (left) and after vacuum-distillation (right). Removal of the coloured contaminants from the FA is clearly visible to the naked eye.

\section{Particle size analysis}

The particle size distributions and related parameters of the powdered carbon samples were determined using a Malvern (UK) Mastersizer 2000 analyzer. Ethanol (99.8\%; Merck, USA) was used to suspend the carbon particles. The procedure for determining the particle size distribution suggested by Malvern was adopted along with their optical parameters for ethanol and activated carbon.

\section{Oxygen chemisorption cycle time}

In the cyclic $\mathrm{O}_{2}$-activation protocol adopted here, the char was exposed to repeated cycles involving first chemisorption under a $100 \mathrm{~mL} \mathrm{~min}^{-1}$ flow of $\mathrm{O}_{2}$ at $250{ }^{\circ} \mathrm{C}$ for 8 hours followed by pyrolysis under a $100 \mathrm{~mL} \mathrm{~min}^{-1}$ flow of argon at $800{ }^{\circ} \mathrm{C}$ for 2 h. The 8 hour period of exposure to oxygen chemisorption was selected by observing via TGA that chemisorption in the non-activated 100 $\mu \mathrm{m}$ char particles is largely complete within this period, as shown in Fig. S2.

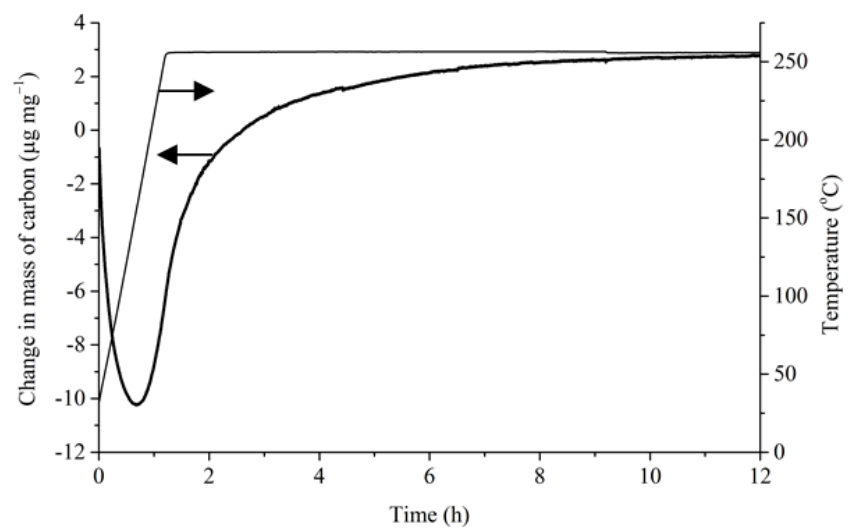

Fig. S2. TGA results for the $\mathrm{O}_{2}$ chemisorption process on the non-activated PFA char. 


\section{Adsorption \& desorption isotherms}

The following show the desorption isotherms alongside the adsorption isotherms for the base samples (B) of each carbon to demonstrate the absence of hysteresis and that equilibration has been achieved at all points along the isotherm. The same is true for attrited samples (not shown).
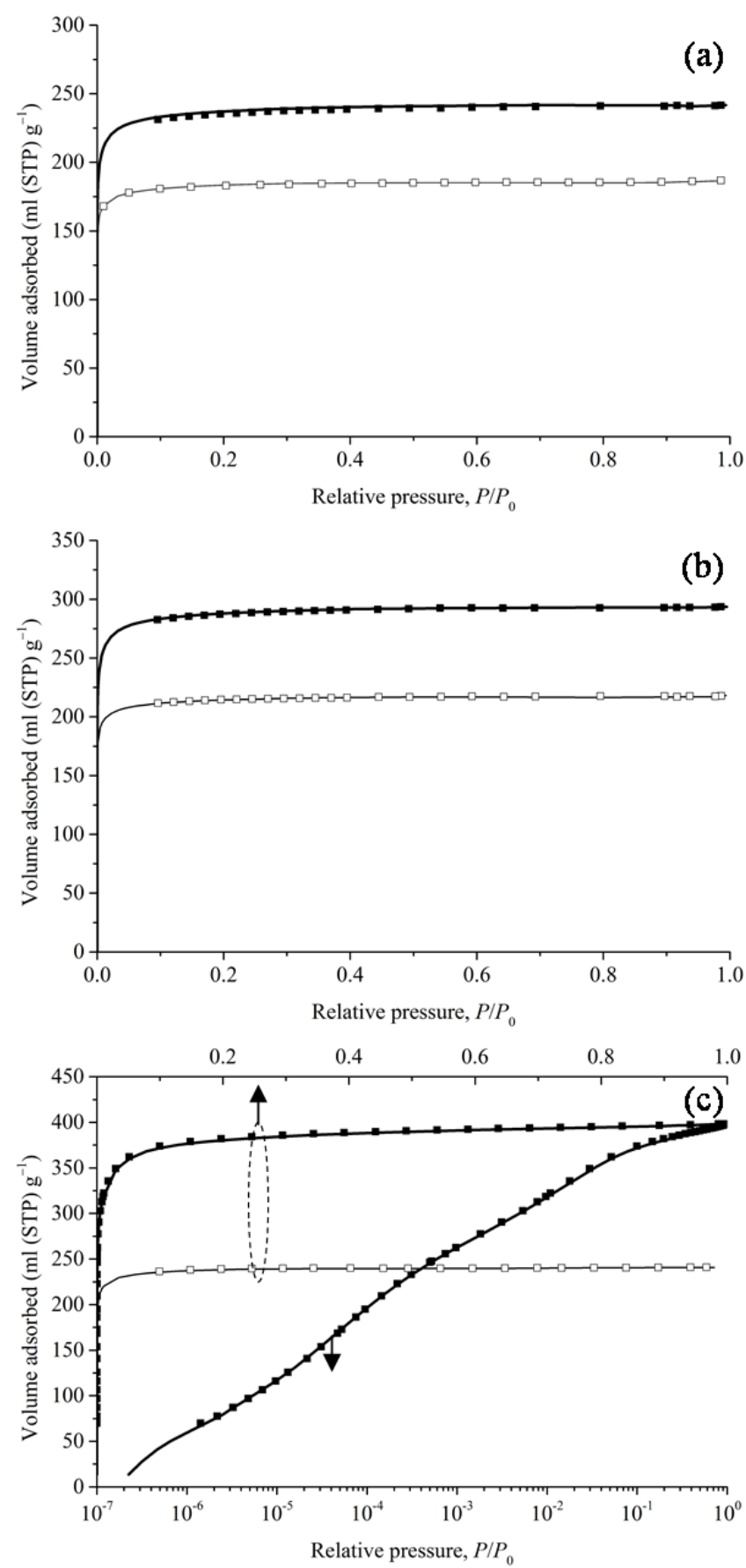

Fig. S3. $\mathrm{N}_{2}$ adsorption (thin \& thick lines for $25 \%$ \& $45 \%$ conversion) \& desorption (open \& closed squares for $25 \% \& 45 \%$ conversion) isotherms at $77 \mathrm{~K}$ : (a) $\mathrm{C}_{2} 5 \mathrm{O}_{2}$ \& $\mathrm{C}_{4} 5 \mathrm{O}_{2}$; (b) $\mathrm{C}_{2} 5 \mathrm{FCO}_{2}$ \& $\mathrm{C}_{45 \mathrm{FCO}}$; and (c) $\mathrm{C}_{2} 5 \mathrm{SCO}_{2} \& \mathrm{C}_{4} 5 \mathrm{SCO}_{2}$.

\section{Isotherms for low-conversion samples}

The following is the low-conversion counterparts of Fig. 5(a) and (b).
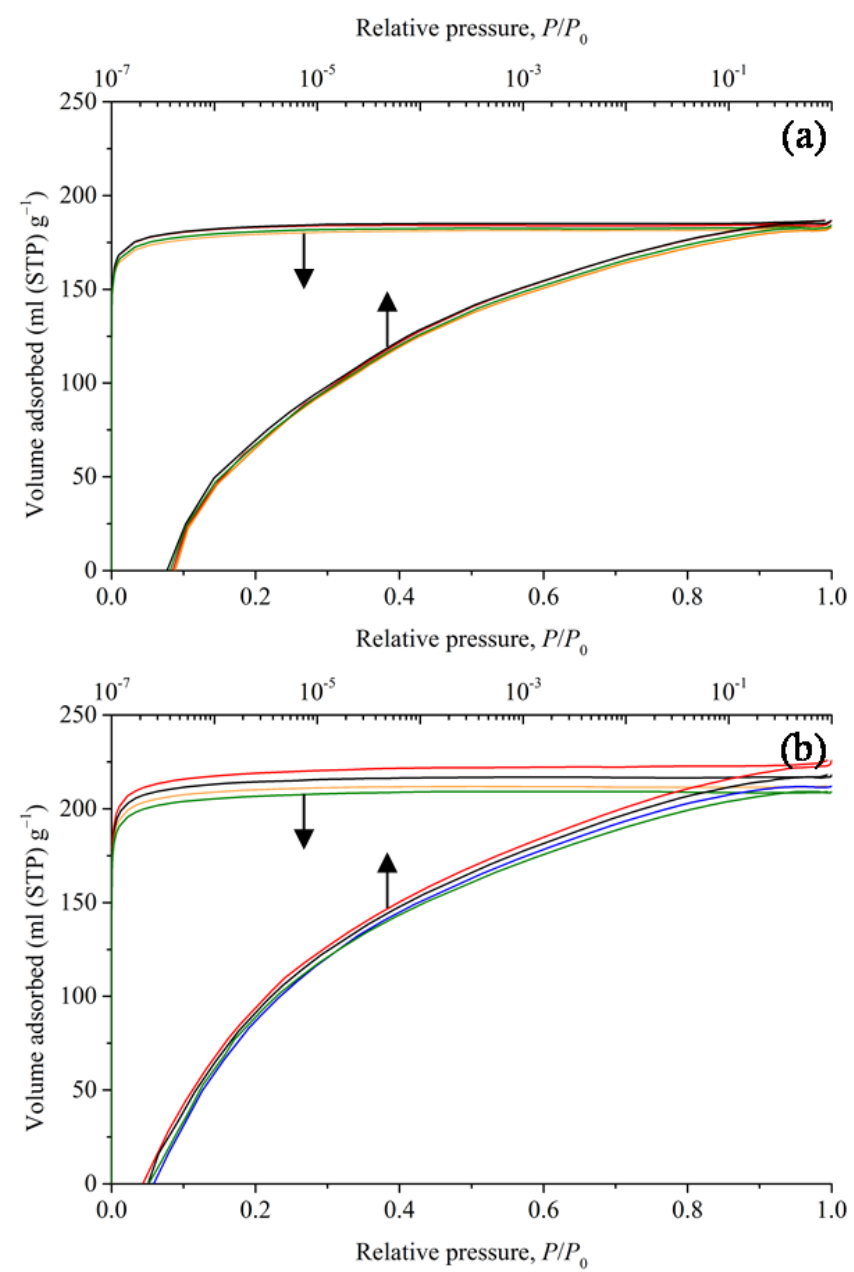

Fig. S4. $\mathrm{N}_{2}$ adsorption isotherms at $77 \mathrm{~K}$ for the $\mathrm{P}$ (red), B (black), C1 (orange) and C2 (green) samples of the low-conversion carbons: (a) $\mathrm{C} 25 \mathrm{O}_{2}$, and (b) $\mathrm{C} 25 \mathrm{FCO}_{2}$. 


\section{PSDs for low-conversion samples}

The following is the low-conversion counterpart

of Fig. 7.
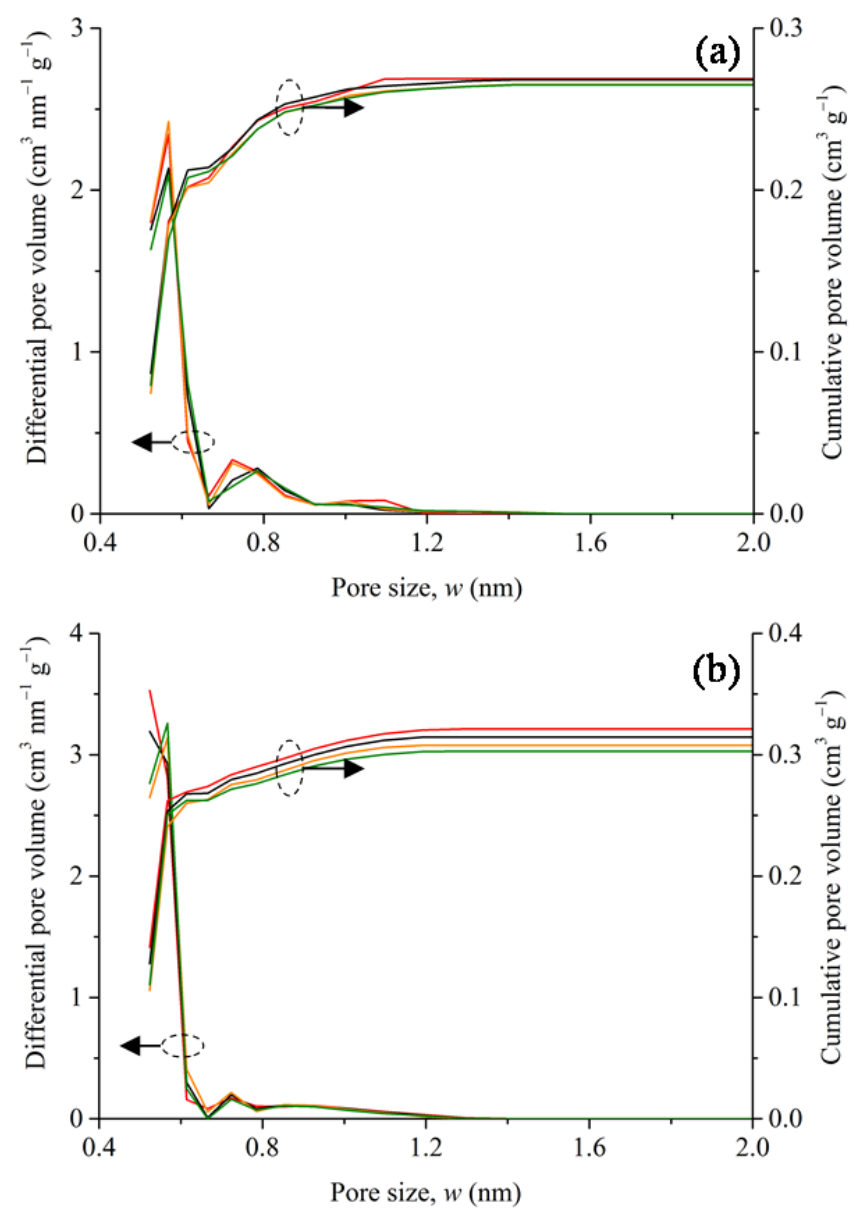

Fig. S5. PSDs for the samples $\mathrm{P}$ (red), B (black), $\mathrm{C} 1$ (orange) and $\mathrm{C} 2$ (green) for: (a) $\mathrm{C}_{25} \mathrm{O}_{2}$; and (b) $\mathrm{C} 25 \mathrm{FCO}_{2}$. 